\title{
El régimen jurídico de la globalización, ¿derecho comercial internacional o derecho económico internacional? ${ }^{1}$
}

\section{The legal regime of globalization, international commercial law or international economic law?}

\section{Carlos F. Forero Hernández²}

(อ).

Recepción: 26/03/2020
(O)

Aprobación: 15/04/2020
(2)

Publicación: 18/12/2020

\section{Para citar este artículo:}

Forero Hernández, C. F. (2020). El régimen jurídico de la globalización, ¿derecho comercial internacional o derecho económico internacional? Indagare, (8), 196-202. https://doi.org/10.35707/indagare/817

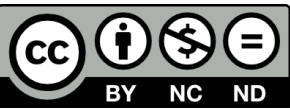

\footnotetext{
${ }^{1}$ Este texto es producto de una actividad académica del módulo "Globalización y Derecho", orientado por el doctor Hugo Fernando Guerrero Sierra, en el Doctorado en Derecho Público de la Universidad Santo Tomás, Tunja.

${ }^{2}$ Grupo de investigación Zoon Politikon, integrante del GEDPE, Universidad de Ibagué, Colombia. ORCID: 0000-00029108-2413. Correo electrónico: carlos.hernandez@unibague.edu.co
} 
INDAGA3E e-ISSN: 2357-5042 • Número 8 (2020) • Universidad de Ibagué • doi: https://doi.org/10.35707/indagare/817

\title{
Resumen
}

El objetivo de este escrito es establecer la diferencia en la comunidad académica sobre la conveniencia de hablar de derecho económico internacional, y no de derecho comercial internacional, cuando nos referimos al régimen jurídico de la globalización; se entiende por derecho económico internacional como el derecho de la internacionalización de los procesos económicos, políticos y culturales. Este tema presenta un enfoque interdisciplinar que vincula el Derecho y la Economía.

\begin{abstract}
The purpose of this paper is to establish the difference in the academic community about the advisability of speaking about International Economic Law rather than International Commercial Law, when we refer to the legal regime of globalization. International Economic Law is understood as the law of the internationalization of economic, political and cultural processes. This topic introduces an interdisciplinary approach that links Law and Economics.
\end{abstract}

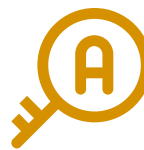

Palabras claves: Globalización, derecho comercial internacional, derecho económico internacional.

Key words: Globalization, international commercial law, international economic law.

\section{Introducción}

De la globalización es muy común afirmar, por ser parte del campo de estudio de las relaciones que se presentan en desarrollo de las actividades comerciales en el orden internacional, que su régimen jurídico es de derecho comercial internacional. No obstante, consideramos que el régimen jurídico de la globalización, por la evidente conexión con el análisis de procesos económicos, políticos y culturales, es de derecho económico internacional entendido como el derecho de internacionalización de los procesos económicos (producción, distribución, comercio y consumo de bienes y servicios), políticos y culturales.

De esta manera, las líneas que siguen pretenden abordar la conveniencia de hablar de derecho económico internacional, y no de derecho comercial internacional, cuando nos referimos al régimen jurídico de la globalización. Para llevar a cabo este tema, es necesario abordarlo de la siguiente manera: 1 . Derecho comercial internacional 
INDAGA]E e-ISSN: 2357-5042 • Número 8 (2020) • Universidad de Ibagué • doi: https://doi.org/10.35707/indagare/817

y derecho económico internacional. Ubicación del tema. 2. La globalización. Aspectos generales. 3. El régimen jurídico de la globalización, ¿derecho comercial internacional o derecho económico internacional?

\section{Método}

Se trata de una investigación con enfoque cualitativo. Por esta razón, este texto explica y profundiza algunas nociones básicas de globalización, derecho económico, derecho económico internacional, derecho comercial internacional. Se elige un diseño secuencial, que comienza con el proceso de recolección y estudio de información cualitativa consistente en la revisión de libros, artículos de investigación, y reflexiones. Una vez conocida la noción de globalización, se analiza su régimen jurídico aplicable, que es el derecho económico internacional, y no derecho comercial internacional. Esta propuesta de conveniencia de hablar de derecho económico internacional, y no de derecho comercial internacional, es cuando nos referimos al régimen jurídico de la globalización, que contribuye a un mejor estudio y a un análisis coherente.

\section{Resultados}

\subsection{Derecho comercial internacional o derecho económico internacional. Ubicación del tema}

En la academia se ha difundido que la más importante división de las ramas del derecho es aquella que las clasifica en normas de derecho público y derecho privado (Narváez, 2011). El primero se ocupa de los asuntos del Estado, en tanto que el segundo estudia los asuntos de los particulares. En el derecho público se encuentran, entre otras ramas: el derecho constitucional, penal, administrativo, procesal, internacional público. En el derecho privado se ubica el derecho civil, derecho comercial, derecho internacional privado, derecho del trabajo, entre otras.

De la anterior explicación, la doctrina se ha preguntado sobre la existencia de un derecho mixto. Este texto coincide con quienes afirman que sí existe un derecho mixto en relación con el derecho público y el derecho privado, cuya denominación es el derecho económico. Barón Barrera (2016), por ejemplo, entiende por derecho económico como "síntesis del derecho público y privado" (p. 35) y explica, además, que este se divide a nivel interno (derecho económico público y privado) y a nivel externo. En este último alude al derecho económico internacional.

Respecto del derecho comercial internacional, se han ofrecido tantas nociones como autores se han ocupado del tema. Muchos autores asocian a esta rama del derecho con el estudio de las actividades comerciales internacionales (Cadena, 2017). Otros 


\subsection{La globalización. Aspectos generales}

En la literatura se encuentran muchas nociones de la globalización. Para este trabajo se comparte la noción elaborada por Serna Mendoza (2004), al señalar que "hace referencia a la creciente internacionalización de los procesos económicos (producción, inversión, comercio), políticos y culturales" (p. 24). La anterior noción permite afirmar que la globalización, para su estudio, se compone de tres procesos: económico, político y cultural. Desde luego el autor en su texto profundizó solamente los procesos culturales, al hacer referencia a la ética y concluye que "la globalización debe tener implícita una ética del bien común, si no va a desencadenar guerras y conflictos en el planeta" (p. 31).

Como se señaló, en la globalización se estudian los componentes: económico, político y cultural. Los procesos económicos no solamente hacen referencia al comercio, a la inversión, sino también a la articulación entre desarrollo humano y desarrollo social, así como lo relacionado con el desarrollo sostenible. Se coincide con quienes afirman que para generar relaciones entre desarrollo humano, desarrollo social y desarrollo sostenible, se requiere de una adecuada aplicación de la educación. La educación es una herramienta para enseñar a los demás a contribuir al desarrollo de los procesos económicos sociales.

En los procesos políticos, además de estudiar con frecuencia la institución de la democracia, se analiza la gobernabilidad, política social del Estado (de las políticas públicas). En estos procesos se identifica la garantía de la capacidad de gobernar y de ejercer un buen gobierno. En un mundo globalizado, cada Estado, para un buen gobierno, requiere de personas altamente capacitadas, con el fin lograr de manera adecuada los objetivos o fines señalados en el ordenamiento jurídico (interno y externo).

En los procesos culturales, se estudia con frecuencia la aplicación de la ética. Se necesita una globalización con ética. Se coincide con la explicación ofrecida por Serna Mendoza (2004), quien afirma que "se hace necesario la conformación de redes y círculos éticos, dado que, con actitudes éticas desde lo personal, se evitan tanto sanciones como auditorías que incrementan costos operacionales" (p. 31).

Corresponde señalar que estos procesos en su ejecución, como es apenas obvio, implican gastos (o costos, para algunos). De ahí que para lograr una globalización eficiente y eficaz, se deben gastar bien los recursos; esto es, invertir de forma adecuada y eficiente. Sostenemos que es idóneo utilizar la denominación gastos y no costos frente a la ejecución de estos procesos, porque está asociada a la noción de gasto social.

Se considera que estas son las principales características de la globalización. Nótese que hasta el momento no se hizo referencia al derecho en la aplicación de la globalización. Se debe señalar que la globalización no está exenta de aplicación del derecho, pues esta (la globalización) no se manifiesta por sí misma, se requiere de 
INDAGA3E e-ISSN: 2357-5042 • Número 8 (2020) • Universidad de Ibagué • doi: https://doi.org/10.35707/indagare/817

normas jurídicas, de ahí la relación con el derecho. Por lo anterior, se pregunta: ¿A qué rama del derecho resulta aplicable la globalización?, ¿derecho público o privado? De esta manera, abordaremos la conveniencia de hablar de derecho económico internacional, y no de derecho comercial internacional, cuando nos referimos al régimen jurídico de la globalización.

\subsection{El régimen jurídico de la globalización, ¿derecho comercial internacional o derecho económico internacional?}

En el campo de estudio de la globalización es común encontrar vínculos con el derecho comercial internacional al hacer referencia a las distintas relaciones que se presentan en desarrollo de las actividades comerciales externas e internacionales. Tal explicación permite entender que en la globalización su régimen aplicable es puro derecho privado. Esta no es una explicación adecuada por cuanto la globalización es susceptible de intervención del Estado (o de los Estados), en caso de distorsiones en el mercado y esto correspondería al derecho público. De esta manera, se puede afirmar que el régimen jurídico de la globalización es mixto en relación con el derecho público y el derecho privado.

Como se explicó, en este texto nos acogemos a la existencia de un derecho mixto cuya denominación corresponde al derecho económico, y este se divide en interno y externo, este último alude al derecho económico internacional. Y como la globalización se caracteriza por la internacionalización de procesos; es decir, a nivel externo; a nuestro juicio su régimen es de derecho económico internacional. A este respecto, coincidimos con las explicaciones ofrecidas por Rivera Sibaja (2008), al señalar estas tres conclusiones: la primera indica que la promoción de medios que dan lugar al intercambio en el plano comercial en el mundo "se conoce como la ideología de la globalización" (p. 2).

La segunda alude a que hay una nueva rama del derecho internacional que surge como respuesta jurídica a esa ideología de globalización: "el derecho económico internacional” (Rivera, 2008, p. 8). Y, finalmente, las principales características lo ubican siempre con la naturaleza propia del derecho internacional público, "pero su especificidad lo remite a la regulación de aspectos económicos para la técnica jurídica" (p. 10). En principio se identifica que el derecho económico internacional corresponde a un derecho internacional público, pero como este no deja de estudiar aspectos económicos, el régimen jurídico de la globalización será un derecho económico internacional. 


\section{Conclusión}

Las consideraciones precedentes permiten concluir que resulta conveniente hablar de derecho económico internacional, y no de derecho comercial internacional, cuando nos referimos al régimen jurídico de la globalización. Entendemos, se reitera, por derecho económico internacional como el derecho de la internacionalización de los procesos económicos, políticos y culturales. Con esta explicación se contribuye a un mejor estudio y a un análisis coherente.

\section{Referencias}

Barón Barrera, G. A. (2016). Transformación del derecho administrativo en derecho económico. Bogotá, Colombia: Ediciones de la U.

Cadena Afanador, W. R. (2017). Derecho mercantil internacional. Bogotá, Colombia: Ediciones ECOE Ediciones - Universidad Militar Nueva Granada.

Narváez, J. I. (2008). Introducción al derecho mercantil. Bogotá, Colombia: Ediciones Legis.

Ravassa Moreno, G. J. (2004). Derecho mercantil internacional. Bogotá, Colombia: Ediciones Doctrina y Ley Ltda.

Rivera Sibaja, G. (2008). Las reglas de la globalización: El derecho económico internacional. Revista de Ciencias Jurídicas, (117), 45-61. Recuperado de https://revistas.ucr.ac.cr/index.php/juridicas/article/ view/9763

Serna Mendoza, C. A. (2004). Globalización sin ética: Guerra sin límites. Asuntos Económicos y Administrativos, 6 (1), 24-33. 